\title{
Development, structure and strength properties of PP/PMMA/FA blends
}

\author{
NAVIN CHAND* and S R VASHISHTHA \\ Regional Research Laboratory, Habibganj Naka, Bhopal 462 026, India
}

MS received 10 September 1999; revised 29 January 2000

\begin{abstract}
A new type of flyash filled PP/PMMA blend has been developed. Structural and thermal properties of flyash (FA) filled polypropylene (PP)/polymethyl methacrylate (PMMA) blend system have been determined and analysed. Filled polymer blends were developed on a single screw extruder. Strength and thermal properties of FA filled and unfilled PP/PMMA blends were determined. Addition of flyash imparted dimensional and thermal stability, which has been observed in scanning electron micrographs and in TGA plot. Increase of flyash concentration increased the initial degradation temperature of PP/PMMA blend. The increase of thermal stability has been explained based on increased mechanical interlocking of PP/PMMA chains inside the hollow structure of flyash.
\end{abstract}

Keywords. Flyash polymer composite; morphology; particulate.

\section{Introduction}

Polypropylene (PP) is a commercially important polymer, which is of practical use in a wide range of applications (Glenz 1986). Its morphology (Frank 1968) means that the mechanical properties of PP are moderate, so if one wants to extend the field of application of this material, an improvement of the mechanical properties is usually necessary. A relative easy way to improve the mechanical properties of a polymer is the addition of filler materials. In general, inorganic fillers are applied to improve the stiffness (Bueche 1962; Nielson 1974), whereas the addition of a rubbery phase is favourable to the toughness of a polymer.

The principal factors which affect mechanical, structural, thermal, electrical and physical properties of polymeric materials, are matrix structure, processing and use of fillers or reinforcements. The filler contents, surface treatment and adhesion between filler and polymer matrix affect the macroscopic and mechanical characteristics of composite materials (Mituishi et al 1988).

Lipatov et al (1976) observed broadening of relaxation time spectra in surface layer of particulate filled PMMA which has been attributed to decrease in number of chain conformations at the interface and to energetic interaction of chains with surface. Flexibility of chains in surface layers could be lowered by conformational restrictions imposed by filler.

Filler influences the performance of the filled polymers (Lisaka and Shibayma 1978). Filler with hydrophilicity or

\footnotetext{
*Author for correspondence
}

polarity and the polymer with polar groups facilitate surface bonding because the surface of filler can be easily wetted by a polymer. Therefore, whether or not the polymer molecule has polarity is an important parameter in determining the reinforcement effect of polymer composites. Chemical bonding between polymer matrix and filler offers good bonding of constituents. In order to have a good interface adhesion between polyolefins and filler, it is necessary for this kind of plastic to bear the polarity before a good affinity with fillers. PMMA is a brittle plastic. Chain stiffness comes in the filled polymer due to absorption of the chains as the filler surface. This change in the chain mobility of surface layer is attributed to formation of hydrogen bond between filler surface and functional group of polymers. Incorporation of glass beads has deduced the molecular motion of PMMA.

In this study, we have developed a new type of flyash filled PP/PMMA blends system. Effect of incorporation of flyash particulate on microstructure, strength and thermal stability has been determined and analyzed. The preliminary character of this study, meant that the aim was not so much to explain in great depth the observed phenomena as to locate points of interest for further research.

\section{Materials and methods}

\subsection{Materials}

The isotectic polypropylene (PP) (Koylene M0030, IPCL) was supplied by Shri Ramdev Plastics, India and commercial grade polymethyl methacrylate (PMMA) was supplied by M/s Monika Plastics, India. Flyash have a 
Table 1. Composition of flyash filled PP/PMMA blend and their tensile strength values.

\begin{tabular}{lccccc}
\hline \multirow{2}{*}{$\begin{array}{l}\text { S1. } \\
\text { no. }\end{array}$} & Sample designation & \multicolumn{3}{c}{ Composition (g) } & \multirow{2}{*}{$\begin{array}{c}\text { Tensile strength } \\
\text { UTS (MPa) }\end{array}$} \\
\cline { 2 - 4 } & PP/PMMA/FA-80/20/00 & 80 & 20 & 00 & $20 \cdot 5$ \\
2 & PP/PMMA/FA-80/20/05 & 80 & 20 & 05 & $17 \cdot 4$ \\
3 & PP/PMMA/FA-80/20/10 & 80 & 20 & 10 & $16 \cdot 5$ \\
4 & PP/PMMA/FA-80/20/15 & 80 & 20 & 15 & $14 \cdot 0$ \\
\hline
\end{tabular}

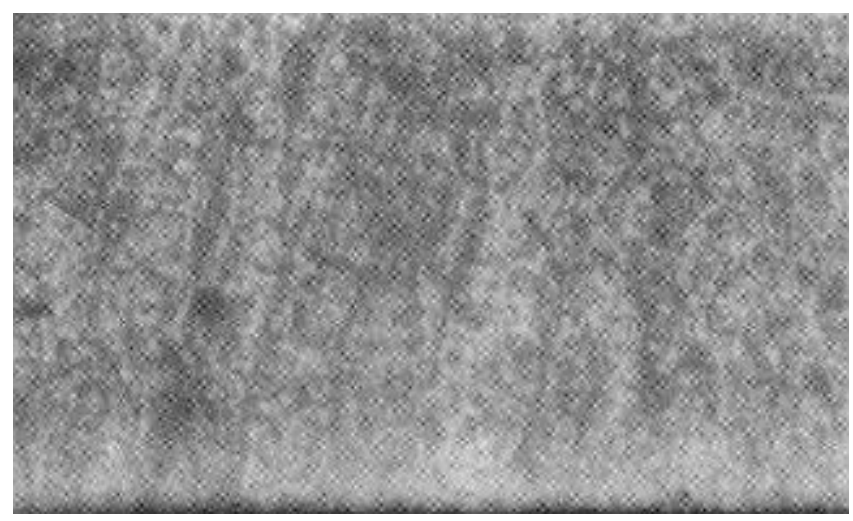

Figure 1. Optical surface microstructure of PP/PMMA $(80 / 20)$ blend.

diameter range of $<45 \mu \mathrm{m}$ and a specific gravity of 2.16. Densities of PP and PMMA were $0.9 \mathrm{~g} / \mathrm{cc}$ and $1 \cdot 19 \mathrm{~g} / \mathrm{cc}$, respectively.

\subsection{Compounding procedure}

PMMA, PP and flyash samples were kept in an aircirculating oven at $70^{\circ} \mathrm{C}$ for $24 \mathrm{~h}$ to dry the materials. Weighed amounts of materials were mechanically mixed. This mixture was then fed into $25 \mathrm{~mm}$ single screw extruder. The barrel temperature was monitored and controlled by thermostats. The die temperature was also controlled by a thermostat and was adjusted, together with barrel temperature to yield uniform output. Feed, compression and metering zone temperatures were 190, 220 and $240^{\circ} \mathrm{C}$, respectively with a die temperature of $220^{\circ} \mathrm{C}$. The extrudates produced in the form of about $2 \mathrm{~mm}$ diameter monofilament were cooled in water. The monofilament produced by using a screw speed of $20 \mathrm{rpm}$ was uniform and opaque, which was cut in the form of granules of 3-4 mm length with the help of a granulater. Compositions of PP/PMMA/FA are given in table 1.

\subsection{Molding process}

A $3 \mathrm{~mm}$ thick sheet was compression molded by hot pressing the granules between hydraulic press at $200^{\circ} \mathrm{C}$.
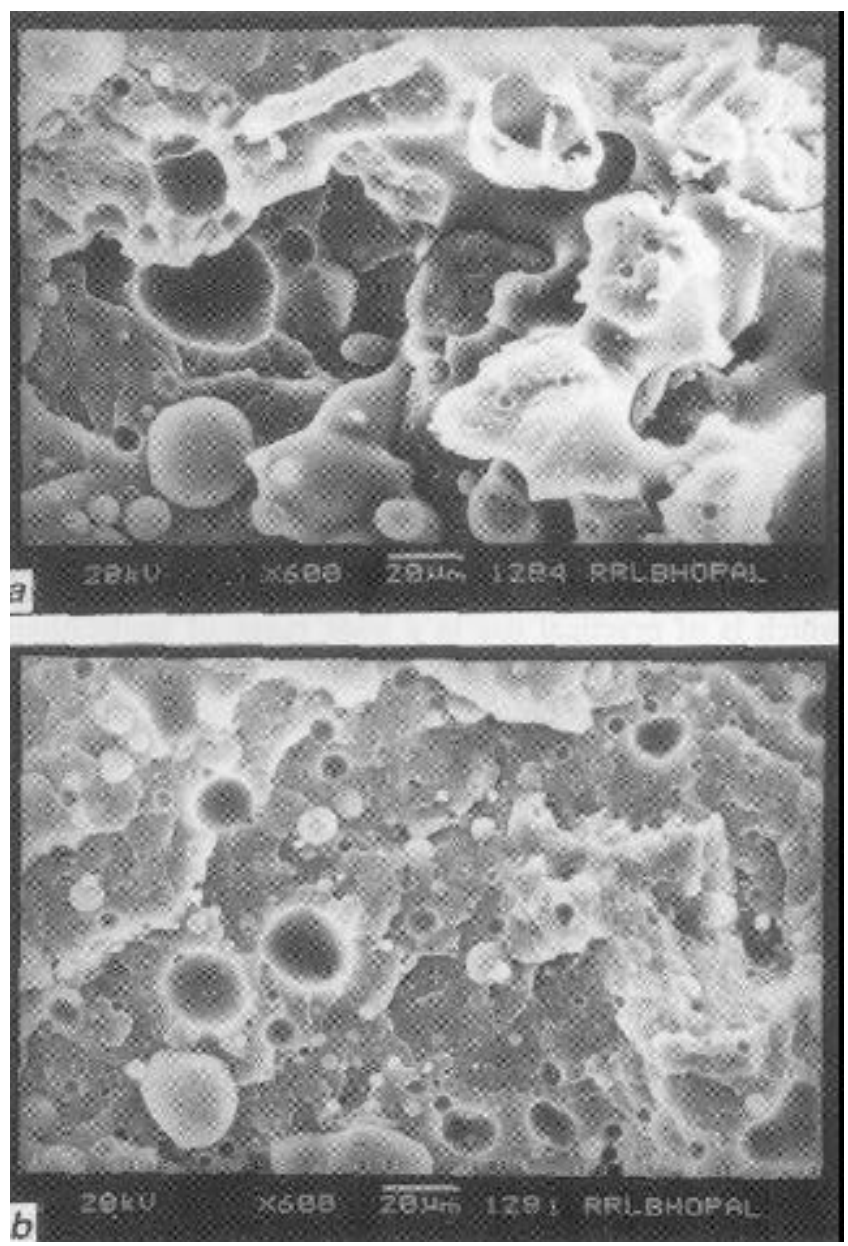

Figure 2. Tensile fractograph of (a) $15 \mathrm{phr}$ flyash filled PP/PMMA (80/20) and (b) unfilled PP/PMMA (80/20) blend.

A pressure of $20 \mathrm{~kg} / \mathrm{cm}^{2}$ was applied for $5 \mathrm{~min}$ to allow the composite to melt and spread out between plates. Pressure was then increased to $200 \mathrm{~kg} / \mathrm{cm}^{2}$ for a further 5 min after the pressure was removed and the sheet was quenched in water at room temperature.

\subsection{Tensile measurement}

Tensile testing measurements were done as per ASTM 638 on a tensile testing machine (INSTRON, 1185) at 
room temperature. A cross head speed of $10 \mathrm{~mm} / \mathrm{min}$ was used.

\subsection{Thermal analysis}

Thermal analysis of samples was done on a Staton Redcroft thermal analyser (model 780 series). Samples of 6-8 $\mathrm{mg}$ were heated from room temperature to $600^{\circ} \mathrm{C}$. TG and DTA data were recorded at $10^{\circ} \mathrm{C} / \mathrm{min}$ heating rate.

\subsection{Surface analysis}

Surfaces of the samples were observed by using Leitz optical microscopy in transmission mode. The fractured morphology of composite was observed by using scanning electron microscope (model JSM 5600). Samples were gold coated before SEM observation.

\section{$2.7 \quad X$-ray measurement}

X-ray analysis of the samples was done on Philips X-ray diffractometer (model 1700). Intensity values were recorded between $10-70^{\circ}, 2 \theta$ angle.

\section{Results and discussion}

Figure 1 shows the microstructure of PP/PMMA blend. It shows that PMMA, which is a brittle polymer, is present as a second phase in PP matrix. PP acts as a matrix and is of white colour in the micrograh spread all over the surface as spherulite and PMMA is in a discrete form as a black portion. PMMA is reported to be in the form of small balls distributed evenly in the PP matrix, which is similar to PP/PC/RM and PP/Nylon-6/RM ternary systems (Hashmi 1996). This system shows the morphology of incompatible blend. Both the phases are observed in the micrographs.

Table 1 lists the tensile values of flyash filled and unfilled blend. It has been found that incorporation of flyash has reduced marginally the tensile strength of the PP/ PMMA blend. Tensile strength of FA filled PP/PMMA composite decreases from 20.5 MPa to $14 \mathrm{MPa}$ on increasing the flyash content from 5 to $15 \mathrm{phr}$. This can be explained based on the reduction in crystallinity of two blends.

Figures $2 \mathrm{a}$ and $\mathrm{b}$ show the tensile fractograph of the 15 phr flyash filled and unfilled PP/PMMA blend. PP and PMMA blend is an incompatible blend. PMMA is found evenly distributed in the form of small balls/globules in PP matrix. Shape of PMMA globules are not uniform and size is in the range $2-30 \mu \mathrm{m}$. It can be seen that the

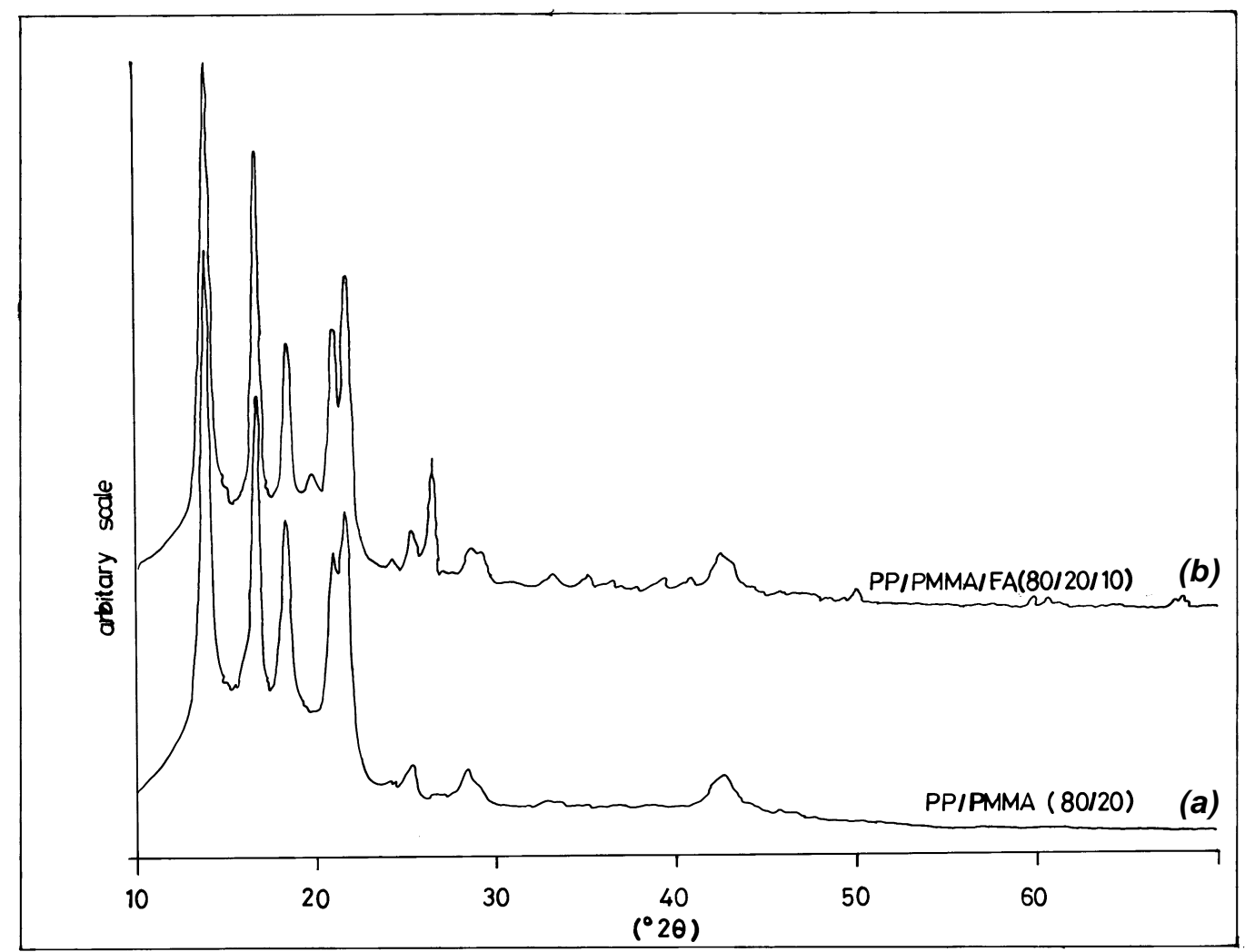

Figure 3. X-ray diffraction pattern of (a) PP/PMMA (80/20) and (b) PP/PMMA/FA (80/20/15). 
globules of the PMMA are poorly bonded with the matrix phase (PP). During fracture of blend it has been observed that PMMA present in the form of globules which comes out and creates cavities and fracture in brittle manner. PP/PMMA blend fractured surface has river pattern type morphology. Due to large differences in melting point of PP and PMMA and lack of co-crystallization owing to the differences in the molecular structure, both the polymers showed incompatibility in the solid state. Combinations of incompatible polymers such as polyolefins and polymethyl methacrylate when prepared by melt blending result in poor dispersion.

Figures $3 \mathrm{a}$ and $\mathrm{b}$ illustrate the X-ray diffraction pattern of PP/PMMA (80/20) and PP/PMMA/FA (80/20/10). The characteristics intensity peaks of PP are found at 13.99 , $16 \cdot 79,18.41$ and $21.7(2 \theta)$ values. Diffraction pattern of FA filled PP/PMMA exhibit all reflections of PP/PMMA blend along with the additional FA peaks (figure $3 \mathrm{~b}$ ). Addition of flyash particles modified the intensities of peaks of crystalline polymer present in the matrix. Addi- tion of flyash particles give additional peaks corresponding to 33.07 ( $\alpha$-quartz), 35.02 ( $\alpha$-quartz), and 49.96 $(\alpha$-quartz, 112) values, respectively. Peak intensity for $2 \theta$ peaks at $13.9,16.7,18.3$ and 21.7 reduced to 3580 from 5098, 2061 from 3709, 1600 from 2520 and 1849 from 2767, respectively. These peaks mainly correspond to PP. The addition of PMMA and FA particles in PP adversely affects the crystallization of PP. Figures $1 \mathrm{a}$ and $\mathrm{b}$ show the globules of PMMA distributed in the PP matrix discontinuously. Addition of flyash particles to PP/PMMA blend increases the discontinuity and restricts the growth of crystal and therefore crystalline peak intensity reduced in the field blend composites. This decrease in crystallinity of PP due to the presence of PMMA at the time of crystallization of PP reduces the strength of PP. This observation of discontinuous morphology is similar to PP/PC/RM and PP/Nylon-6/RM systems reported earlier (Hashmi 1996).

Figure 4 shows the effect of addition of flyash particles on thermal stability of PP/PMMA blend. Lower curve A

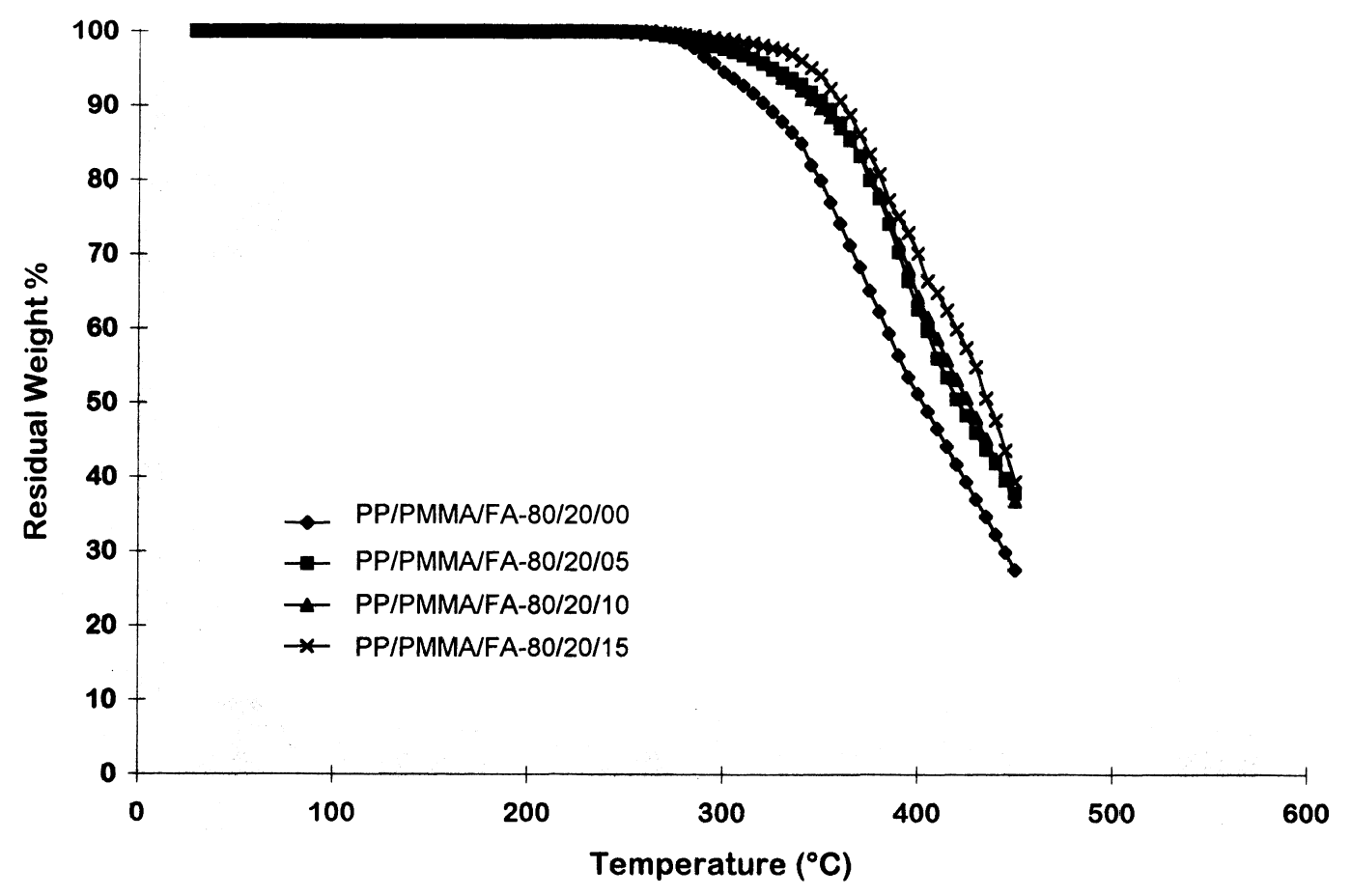

Figure 4. Effect of addition of flyash particles on thermal stability of PP/PMMA blend.

Table 2. Thermal data of filled and unfilled PP/PMMA blends.

\begin{tabular}{lccccc}
\hline $\begin{array}{l}\text { S1. } \\
\text { no. }\end{array}$ & \multicolumn{2}{c}{ Melting temperature } & $\begin{array}{c}\text { Initial degradation } \\
\text { temperature }\left({ }^{\circ} \mathrm{C}\right)\end{array}$ & $\begin{array}{c}\text { Temperature of } \\
50 \% \text { degradation }\end{array}$ & $\begin{array}{c}\text { Residual weight } \\
(\%)\end{array}$ \\
\hline 1 & 168 & 160 & 248 & 360 & 3 \\
2 & 168 & 160 & 256 & 399 & 8 \\
3 & 168 & 160 & 260 & 409 & 13 \\
4 & 168 & 160 & 260 & 419 & 18 \\
\hline
\end{tabular}


belongs to unfilled PP/PMMA blend and B, C, D corresponds to 5,10 and $15 \mathrm{phr}$ FA filled PP/PMMA blend composite. Initial degradation position, listed in table 2 for filled and unfilled blends, shifts to higher temperature side on increasing the flyash content from 5 to $15 \mathrm{phr}$. All the curves show a single stage degradation pattern. FA filled PP/PMMA blend shows improved thermal stability, which is due to addition of flyash. In the PP/PMMA/FA composites, relative thermal stability has the following order

$$
80 / 20 / 15>80 / 20 / 10>80 / 20 / 5>80 / 20 / 00 \text {. }
$$

Table 2 lists the melting temperature $\left(T_{\mathrm{m}}\right)$, initial degradation temperature (IDT), temperature of $50 \%$ degradation $\left(T_{\mathrm{D} 50}\right)$ and residual weight per cent of flyash filled and unfilled PP/PMMA composites.

\section{Conclusions}

(I) A new type of cheaper blend is developed by melt mixing technique.

(II) Incorporation of flyash modifies the PP/PMMA structure by interlocking the chains on the surface and inside the flyash particles.

(III) An increase in flyash content raises the thermal stability of PP/PMMA blend.

\section{References}

Bueche F 1962 Physical properties of polymers (New York: Interscience Publishers)

Frank H P 1968 'Polypropylene' polymer monographs (New York: Gordon and Breach Science) Vol 2

Glenz W 1986 Kunstoffe 76834

Hashmi S A R 1996 Development of redmud filled polymer composite and their rheological, tribological and mechanical properties, Ph.D. Thesis, Barkatullah University, Bhopal

Lipatov Y S, Babich V F and Rosovizky V F 1976 J. Appl. Polym. Sci. 201787

Lisaka K and Shibayma K 1978 J. Appl. Polym. Sci. 223135

Mitsuishi K, Kodama S and Kawasaki H 1988 Polym. Comp. 9 112

Nielsen L E 1974 Mechanical properties of polymers and composites (New York: Marcell Dekker) Vols 1 \& 2 